\title{
Required Lateral Inlet Pressure Head for Automated Subsurface Drip Irrigation Management
}

\author{
Moncef Hammami, ${ }^{1}$ Khemaies Zayani, ${ }^{2}$ and Hédi Ben $\mathrm{Ali}^{3}$ \\ ${ }^{1}$ University of Carthage, High School of Agriculture of Mateur, 7030 Mateur, Tunisia \\ ${ }^{2}$ University of Carthage/High Institute of Environmental Sciences and Technologies of Borj Cedria, \\ B.P. 1003, 2050 Hammam Lif, Tunisia \\ ${ }^{3}$ Agricultural Investment Promotion Agency, 6000 Gabès, Tunisia \\ Correspondence should be addressed to Moncef Hammami; hammami.moncef@ymail.com
}

Received 13 March 2013; Revised 14 May 2013; Accepted 29 May 2013

Academic Editor: Vicente Gimeno

Copyright (C) 2013 Moncef Hammami et al. This is an open access article distributed under the Creative Commons Attribution License, which permits unrestricted use, distribution, and reproduction in any medium, provided the original work is properly cited.

\begin{abstract}
Subsurface drip irrigation (SDI) is one of the most promising irrigation systems. It is based on small and frequent water supplies. Because SDI emitters are buried, their discharges are dependent on the water status at the vicinity of the outlets. This paper was targeted to design the SDI laterals accounting for the soil water-retention characteristics and the roots water extraction. The proposed approach provides systematic triggering and cut-off of irrigation events based on fixed water suctions in the vadose zone. In doing so, the soil water content is maintained at an optimal threshold ascertaining the best plant growth. Knowing the soil water-retention curve, the appropriate water suction for the plant growth, and the emitter discharge-pressure head relationship, the developed method allows the computation of the required hydraulics of the lateral (e.g., inlet pressure head, inside diameter, etc.). The proposed approach is a helpful tool for best SDI systems design and appropriate water management. An illustrative example is presented for SDI laterals' design on tomato crop.
\end{abstract}

\section{Introduction}

In subsurface drip irrigation (SDI), water seeps from the buried emitters into the soil and spreads out in the vadose zone under the conjugate effect of capillary and gravity forces $[1,2]$. Thus, SDI system allows the direct application of water to the rhizosphere maintaining dry the nonrooted topsoil. This pattern generates numerous advantages such as minimizing soil evaporation and then evapoconcentration phenomenon. The rationale is that SDI improves the water application uniformity, increases the laterals and emitters longevity, reduces the occurrence of soil-borne diseases, and allows the control of weeds infestation. Several field trials revealed relevant profits on managing SDI for crop production. Nevertheless, the appropriate depth of buried laterals remains debatable [3-6]. Comparing evaporation from surface and subsurface drip irrigation systems, Evett et al. [7] reported that $51 \mathrm{~mm}$ and $81 \mathrm{~mm}$ were saved with drip laterals buried at $15 \mathrm{~cm}$ and $30 \mathrm{~cm}$, respectively. Neelam and
Rajput [1] recorded maximum onion yield $\left(25.7 \mathrm{tha}^{-1}\right)$ with drip laterals buried at $10 \mathrm{~cm}$. According to these authors, the maximum drainage occurred when drip laterals are laid at $30 \mathrm{~cm}$ depth. On the other hand, numerous studies were devoted to the analysis of the effect of the soil properties on the SDI emitters discharge and water distribution uniformity [8-10]. The analytical approach proposed by Sinobas et al. [2] predicts reasonably well the soil water suction and the pressure head distributions in the laterals and SDI units [11].

The water oozes from the buried emitters under the conjugate effect of the inlet lateral pressure head and the water suction in the surrounding soil. Therefore, the emitter discharge is high at the beginning of watering because the root zone is yet relatively dry. Gradually, as the pore space at the dripper outlet is filled with water, a positive pressure head develops, which may cause a decrease in dripper discharge [12]. If the discharge is larger than the infiltration capacity, the resulting overpressure near the nozzle tends to lessen the flow rate $[9,13]$. It should be stressed that the overpressure 
phenomenon is more likely to occur near the emitter outlet in fine textured soils than in coarse ones. Indeed under field conditions, Shani et al. [12] highlighted that the pressure head increases rapidly up to $8 \mathrm{~m}$ after 10 to 15 minutes of irrigation in fine soil. For similar soil and flow rate conditions, Gil et al. [14] obtained lower overpressures in pots. They observed that the greater the emitter flow rate is, the higher the overpressure will be.

The emitter flow rate is a power function of the pressure head difference between the nozzle's inlet and outlet. The increase of the pressure head at the emitter outlet induces a flow-rate decrease. Reciprocally, plant roots water uptake generates soil drying. Thus, the resulting decrease of the soil pressure head fosters an increase of the emitter flow rate and/or the energy saving [15]. Accordingly, the emitter discharge variations are governed by the soil moisture variations and the roots water uptake. To reap the best from this opportunity, the SDI systems design should account for the influence of soil water status on the buried emitters discharge. Lazarovitch [16] and Clothier and Green [17] recommended the use of sufficiently low flow rates to match the roots water uptake. This paper is devoted to the development of a new approach to design SDI systems for a systematic irrigation management, energy saving, and least labor cost.

\section{Basics of the Approach}

The pressurized irrigation systems are customarily designed so that the mean pressure head throughout the pipe is equal to the nominal pressure head. On the other hand, irrigation management is based on the replenishment of the soil holding capacity. Hence, the soil moisture should range between predetermined and minimum allowable water contents. Hereinafter, we assume that the average pressure head is equal to the emitter operating pressure head. The emitter discharge equation may be expressed by [18]

$$
q=K H^{x}
$$

where $q\left[\mathrm{~L}^{3} \mathrm{~T}^{-1}\right]$ and $H[\mathrm{~L}]$ are the emitter discharge and the emitter pressure head, whereas $K\left[\mathrm{~L}^{3-x} \mathrm{~T}^{-1}\right]$ and $x[-]$ are fitting parameters.

Equation (1) is valid for a pressure head higher than or equal to $5.0 \mathrm{~m}$. It is worth pointing out that most long-path turbulent flow emitters and pressure-compensating outlets require an operating pressure head fulfilling this condition. For buried emitters, the emitter pressure head is lumped with the water suction near the outlets:

$$
H=h_{e}-h_{i},
$$

where $h_{e}$ and $h_{i}$ refer to the pressure heads [L] at the inner and outer tips of the emitter, respectively. For emitters laid on the ground, $h_{i}$ is the atmospheric pressure. Conversely, for buried emitters, $h_{i}$ is a spatial-temporal variable dependent on the prevailing soil water content. Hereinafter, we will consider the sigmoid retention curve of Van Genuchten [19] as follows:

$$
\theta=\theta_{r}+\frac{\left(\theta_{s}-\theta_{r}\right)}{\left[1+(\alpha h)^{n}\right]^{m}}
$$

where $\theta\left[\mathrm{L}^{3} \mathrm{~L}^{-3}\right]$ and $h[\mathrm{~L}]$ refer to the volumetric water content and to the soil suction head, respectively. The residual water contents $\theta_{r}, \alpha\left[\mathrm{L}^{-1}\right], n$, and $m$ are inferred by fitting scattered data $(\theta, h)$ according to (3), and $\theta_{s}$ refers to the saturated soil water content. The dimensionless parameters $n$ and $m$ are expressed by the Mualem [20] relationship as follows:

$$
m=1-\frac{1}{n}
$$

The soil capillary capacity $C\left[\mathrm{~L}^{-1}\right]$ is derived straightforwardly by differentiating (3) with respect to the suction head as follows:

$$
C=\frac{d \theta}{d h}=\frac{-m n \alpha\left(\theta_{s}-\theta_{r}\right)\left(\alpha h^{n-1}\right)}{\left[1+(\alpha h)^{n}\right]^{m+1}} .
$$

Equation (5) shows that additional increase of the suction head produces an additional water release from the soil. Besides, the value of $C$ is the highest if the second derivative of the soil moisture content with respect to the suction head is zero. Under these conditions, the crops absorb the maximum water from the root zone for the same additional energy increment. Further analysis provides the coordinates of the inflexion point of the retention curve as well as the maximum capillary capacity as follows:

$$
\begin{gathered}
h_{\mathrm{op}}=\frac{-m^{1 / n}}{\alpha}, \\
\theta_{\mathrm{op}}=\theta_{r}+\frac{\left(\theta_{s}-\theta_{r}\right)}{(1+m)^{m}}, \\
C_{\max }=\frac{n m^{m+1} \alpha\left(\theta_{s}-\theta_{r}\right)}{(1+m)^{m+1}},
\end{gathered}
$$

where $h_{\mathrm{op}}, \theta_{\mathrm{op}}$, and $C_{\max }$ refer to the optimal water suction, optimal soil water content, and maximum capillary capacity, respectively. Therefore, the design of SDI systems should ascertain a suction head at the emitter outlet that matches the optimal water status within the root zone. Combining (1) and (2) yields the following:

$$
q=K\left(h_{e}-h_{\mathrm{op}}\right)^{x}
$$

Equations (6) and (7) highlight the dependence of the emitter discharge on the pressure heads at the inner and outer tips of the nozzle. Inasmuch as the soil is more or less dry at the beginning of the irrigation, the discharge decreases with the elapsed time. Incidentally as the soil becomes wetter, the soil pressure head increases and the emitter discharge stabilizes to a minimum value. Experimental results of Gil et al. [14] showed that the decrease of the flow rate is steeper in loamy than in sandy soils. Yao et al. [13] recorded that the wetted soil volume in medium loam and sandy loam is virtually invariant as the inlet pressure head increased from 60 to $150 \mathrm{~cm}$. This increase of pressure head may lead to the backpressure development. Yao et al. [13] recommended that the emitter discharge should be matched to the soil conditions, 
so that back-pressure occurrence is avoided. According to Ben-Gal et al. [21] and Lazarovitch et al. [9], one of the main issues with SDI systems is the soil saturation. This phenomenon induces temporary asphyxia of crops and may stop the emitter discharge even though the moistened bulb is not yet spatially well extended.

According to (1) and (2), the emitter discharge is null whenever the outlet pressure head $\left(h_{i}\right)$ matches the predetermined inlet one $\left(h_{e}\right)$. Afterwards, the redistribution process provides drier rooted soil profiles. Subsequently, the pressure near the emitter $\left(h_{i}\right)$ decreases until the pressure differential between the outlet tips overtakes a minimum value $\Delta h_{\min }$ required for the emitter operation. This threshold $\Delta h_{\text {min }}$ is dependent on the structural form, dimension, and material of the emitter pathway. For any emitter model, $\Delta h_{\min }$ may be inferred from the emitter discharge-pressure head relationship provided by the manufacturer.

Thus, the next irrigation is automatically triggered once the following inequality is fulfilled:

$$
h_{e}-h_{i}=h_{e}-h_{\mathrm{op}} \geq \Delta h_{\min } .
$$

Therefore, the required minimum pressure head at the emitter inlet $h_{\min }^{*}$ should comply with

$$
h_{\min }^{*} \geq h_{\mathrm{op}}+\Delta h_{\min } .
$$

It is worth emphasizing that the suction head at the vicinity of the emitter cannot be lastingly maintained constant and equal to $h_{\mathrm{op}}$. Unavoidable fluctuations of the suction head are expected owing to evapotranspiration and water redistribution processes. For the sake of convenience, the suction head in the root zone should be circumscribed within a prescribed interval $\left[h_{\mathrm{op}}+\Delta h_{\mathrm{op}}, h_{\mathrm{op}}-\Delta h_{\mathrm{op}}\right]$. Therefore, the minimum required emitter inlet pressure head $h_{\mathrm{req}}^{\mathrm{min}}$ is given by

$$
h_{\text {req }}^{\min }=h_{\mathrm{op}}-\Delta h_{\mathrm{op}}+\Delta h_{\mathrm{min}},
$$

whereas the maximum required emitter inlet pressure head $h_{\text {req }}^{\max }$ is given by

$$
h_{\mathrm{req}}^{\max }=h_{\mathrm{op}}+\Delta h_{\mathrm{op}}+\Delta h_{\mathrm{min}} .
$$

The magnitude of the interval $\left[h_{\mathrm{op}} \pm \Delta h_{\mathrm{op}}\right]$ should account for the sensitivity of the crop to the water stress. As a matter of fact, for tomato crop, the reduction of the water requirement by $20 \%$ produces $20 \%$ yield decrease [22]. Contrariwise, the decrease of the onion water requirement by $20 \%$ induces only $2 \%$ of yield decrease [5]. It should be highlighted that these yield reductions are more or less significant according to the physiological stages.

\section{The Required Lateral Pressure Head}

For a buried lateral equipped with $N$ identical emitters, the inlet discharge $Q$ will vary within the following limits:

$$
N q_{\min } \leq Q \leq N q_{\max },
$$

TABLE 1: Tolerable soil pressure head variations for some crops.

\begin{tabular}{lccc}
\hline Crop & $\begin{array}{c}\text { Upper pressure } \\
(\mathrm{cm})\end{array}$ & $\begin{array}{c}\text { Lower pressure } \\
(\mathrm{cm})\end{array}$ & References \\
\hline Spring wheat & -25 & -1000 & $\begin{array}{c}\text { Li et al. [23] } \\
\text { Gärdenäs et al. } \\
\text { Tomato }\end{array}$ \\
& -2 & -800 & [24] \\
Soybeans & -25 & -800 & $\begin{array}{c}\text { Clemente et al. } \\
{[26]}\end{array}$ \\
Grape & -2 & -1000 & $\begin{array}{c}\text { Hanson et al. [25] } \\
\text { Clemente et al. } \\
\text { Grass }\end{array}$ \\
\hline
\end{tabular}

where $q_{\max }$ and $q_{\min }$ are the maximum and minimum emitters average discharges, respectively. For design purpose, only the maximum average emitters discharge is considered. Therefore, the lateral inner diameter is designed to allow the conveyance of the upper bound of the discharge. Consequently, the minimum pressure head required at the upstream end of nontapered flat lateral is

$$
h_{L m}=Z_{d}+J_{L}+\Delta h_{\mathrm{min}}+h_{\mathrm{op}}-\Delta h_{\mathrm{op}}
$$

whereas the maximum pressure head required at the upstream end of the lateral is

$$
h_{L M}=Z_{d}+J_{L}+\Delta h_{\min }+h_{\mathrm{op}}+\Delta h_{\mathrm{op}}
$$

with $Z_{d}[\mathrm{~L}]$ and $J_{L}[\mathrm{~L}]$ being the emitters burial depth and the head loss along the lateral, respectively. By convention, the gravitational potential $Z_{d}$ is computed negatively downwards.

According to the aforementioned basics, the design procedure of SDI systems should lead to the automation of water supplies. Indeed, the irrigation events are triggered whenever the mean pressure head within the root zone is reduced to the minimum prescribed value $\left(h_{\mathrm{op}}-\Delta h_{\mathrm{op}}\right)$. They would be automatically ended once the pressure head within the root zone exceeds the maximum value $\left(h_{\mathrm{op}}+\Delta h_{\mathrm{op}}\right)$. From theoretical standpoint, a self-regulation of the flow rate by soil water properties and moisture conditions should prevail. Moreover, the emitters discharge variations due to the head losses are offset by soil pressure head gradients. Accordingly, the irrigation events as well as the uniformity of the flow rates are controlled by the soil suction head at the emitters depth of burial. These results corroborate those obtained by Gil et al. [14] who recorded higher flow rates' variability with surface emitters than with buried ones.

Tolerable soil pressure head variations for some crops are summarized in Table 1.

It is worth pointing out that the abovementioned approach remains valid regardless of the used soil water-retention relationship. The following steps summarize the proposed design procedure of SDI laterals. 


\section{The Design Steps}

(1) Carry out simultaneous in situ field measurements of moisture contents and suction heads.

(2) Fit the experimental dataset $(\theta, h)$ in accordance with the appropriate soil water-retention curve (for instance, (5)).

(3) Derive twice the moisture content with respect to the suction head and infer $h_{\mathrm{op}}$.

(4) Select the proper interval of the soil suction head $\Delta h_{\mathrm{op}}$ for the considered crop (for instance, data provided in Table 1).

(5) For the used emitters type, calculate the minimum inlet pressure head $h_{\min }^{*}$ using (9).

(6) Calculate the minimum and maximum required emitter inlet pressure heads using (10a) and (10b), respectively.

(7) Using (11), calculate the required lateral inlet discharge.

(8) Deduce the minimum and maximum required lateral inlet pressure heads, using (12a) and (12b), respectively.

\section{Study Case}

To illustrate the proposed procedure, let us consider a polyethylene nontapered flat pipe $100 \mathrm{~m}$ long with equidistant in line-emitters spaced $0.40 \mathrm{~m}$. The laterals irrigate tomato crop on homogeneous sandy soil. Following Patel and Rajput [5], the emitters depth is $15 \mathrm{~cm}$. Therefore, the design steps are the following.

(1) Simultaneous in situ measurements of the soil water contents and suction heads were performed [27] on three randomized points during water redistribution. In each soil profile, suction heads were measured using three tensiometers installed at 10,30, and $50 \mathrm{~cm}$ depth. Soil cores sampled at the same depths were used to determine gravimetrically the correspondent soil water contents. For each depth, the average of the three measurements was considered.

(2) Experimental data were fitted in accordance to the Van Genuchten [19] model [27]. Scattered and fitted data are depicted in Figure 1. The inferred fitting parameters $\left(\theta_{r}, m, n\right.$, and $\alpha$ ) are summarized in Table 2 .

(3) Using (6), the optimum suction head $h_{\mathrm{op}}$ is approximately $-12 \mathrm{~cm}$. This value is within the optimal range of the suction head for tomato crop $[24,25]$. To prevent asphyxia risk or relative water stress at upper $(-2 \mathrm{~cm})$ and lower $(-800 \mathrm{~cm})$ tolerable pressure heads, $\Delta h_{\mathrm{op}}$ being equal to $400 \mathrm{~cm}$ is acceptable.

(4) Thus, the prescribed soil pressure head limits for tomato crop are the following:

$$
\begin{gathered}
h_{\mathrm{op}}-\Delta h_{\mathrm{op}} \approx-12-400 \mathrm{~cm}=-412 \mathrm{~cm}, \\
h_{\mathrm{op}}+\Delta h_{\mathrm{op}} \approx-12+400=388 \mathrm{~cm} .
\end{gathered}
$$

In order to avoid eventual back-pressure development, the suction head should be maintained within $[-412 \mathrm{~cm}, 0.0 \mathrm{~cm}]$.

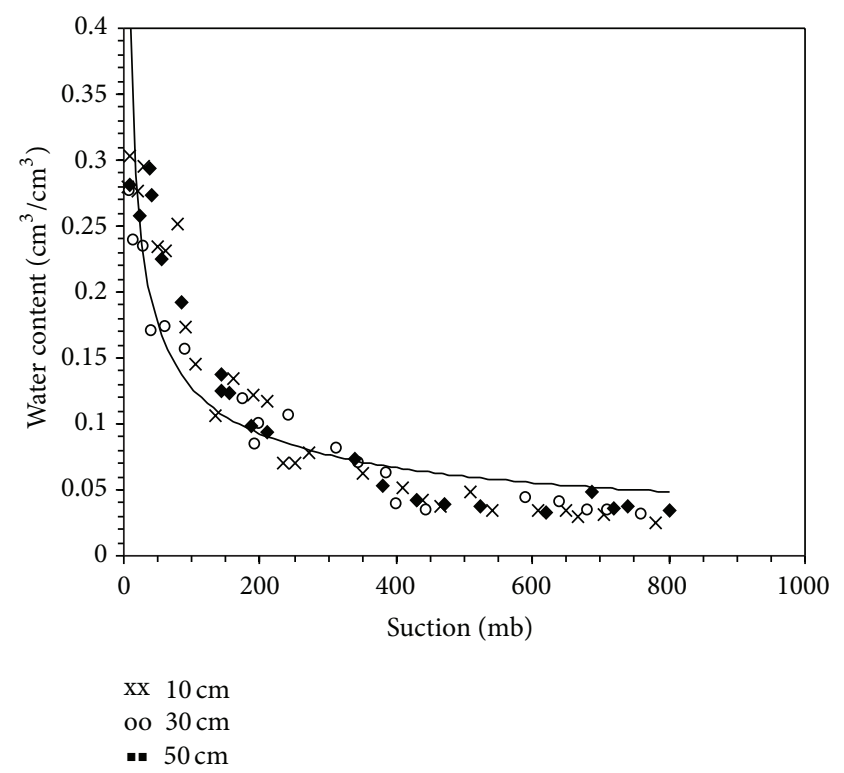

FIGURE 1: Water retention curve: measured data at different soil depths.

TABle 2: Fitting parameters of Van Genuchten's equation for the considered sandy soil.

\begin{tabular}{lcccc}
\hline$\theta_{s}\left(\mathrm{~cm}^{3} / \mathrm{cm}^{3}\right)$ & $\theta_{r}\left(\mathrm{~cm}^{3} / \mathrm{cm}^{3}\right)$ & $\alpha\left(\mathrm{cm}^{-1}\right)$ & $n$ & $R^{2}$ \\
\hline 0.38 & 0.02 & 0.05 & 1.70 & 0.991
\end{tabular}

(5) A trapezoidal labyrinth long-path emitter with a minimal differential operating pressure head of $\Delta h_{\min }=$ $500 \mathrm{~cm}$ is used. The discharge-pressure head relationship of these emitters is [28]

$$
q=0.752\left(h_{e}-h_{i}\right)^{0.478}
$$

where $q=$ emitter discharge $(1 / \mathrm{h}), h_{e}=$ the emitter inlet pressure head $(\mathrm{m})$, and $h_{i}=$ the emitter outlet pressure head (m).

(6) Using (10a) and (10b), the required emitter inlet pressure $h_{\text {req }}$ should comply with

$$
(-12-400+500)=88 \leq h_{\text {req }}(\mathrm{cm}) \leq(0+500)=500 .
$$

To maintain an optimal suction head within the root zone $(-12 \mathrm{~cm})$ and to compensate the minimum differential operating pressure head $\left(\Delta h_{\min }=500 \mathrm{~cm}\right)$, the optimal required emitter inlet pressure would be $h_{\text {oreq }}=(-12+500)=488 \mathrm{~cm}$. Compared with the pressure heads customarily required for on-surface drippers (approximately $1000 \mathrm{~cm}$ ), the obtained value underlines an outstanding energy saving with SDI systems. Thus, according to (14), the corresponding emitter discharge $q$ is given as

$$
\begin{aligned}
0.752[0.88-0.00]^{0.478} & =0.707 \leq q(\mathrm{l} / \mathrm{h}) \\
& \leq 0.752[5.00-(-4.12)]^{0.478} \\
& =2.163 .
\end{aligned}
$$


As long as the lowest differential pressure head $(0.88 \mathrm{~m})$ is less than the minimum differential operating pressure head $\left(\Delta h_{\min }=500 \mathrm{~cm}\right)$, the emitter discharge should lay within the interval $[0.00,2.163]$. Nevertheless, the optimal required emitter discharge matching the optimal soil suction head $q_{\text {op }}$ would be

$$
q_{\mathrm{op}}=0.752[4.88-(-0.12)]^{0.478} \approx 1.623 \mathrm{l} / \mathrm{h} .
$$

(7) The number of emitters along the lateral equals $100 \mathrm{~m} / 0.4 \mathrm{~m}=250$. According to (11), the optimal required discharge at the lateral inlet tip is

$$
Q_{\mathrm{op}}=250 \times 1.623=405.75 \mathrm{l} / \mathrm{h} \text {. }
$$

The head loss gradient $j$ may be estimated by Watters and Keller's formula [29] as

$$
j=\alpha Q^{\beta} D^{-\gamma},
$$

where $Q$ and $D$ are the discharge and the lateral inner diameter, respectively. For $j(\mathrm{~m} / \mathrm{m}), Q(\mathrm{l} / \mathrm{h})$, and $D(\mathrm{~mm})$, the parameters of (19) are $\beta=1.75, \gamma=4.75$, and $\alpha=$ $14.709598 v^{0.25}$ where $v\left(\mathrm{~m}^{2} \mathrm{~s}^{-1}\right)$ refers to the kinematic viscosity of water. At $20^{\circ} \mathrm{C}, \alpha$ is equal to 0.4655 . Considering (19) and an inner diameter of $16 \mathrm{~mm}$, the head loss throughout the lateral $J_{L}$ is given by [29]

$$
\begin{aligned}
J_{L} & =\frac{\alpha Q_{\max }^{\beta} D^{-\gamma}}{1+\beta} L=\frac{0.4655(405.75)^{1.75}(16.0)^{-4.75}}{1+1.75} 100 \\
& =1.184 \mathrm{~m}
\end{aligned}
$$

This value would be doubled if we account for the emitters connection head losses as computed by the Juana et al. [30] approach.

(8) Using (12a) and (12b) and accounting for emitters connection head losses, the required pressure head at the inlet tip of the lateral would be

$$
\begin{aligned}
(-15 & +2 * 118.4+500-12-400) \\
& =309.8 \leq h_{L}(\mathrm{~cm}) \\
& \leq(-15+2 * 118.4+500+0)=721.8 .
\end{aligned}
$$

In the same way, the optimal required pressure head $h_{\mathrm{Lo}}$ at the lateral inlet would be

$$
h_{\text {Lo }}=(-15+2 * 118.4-12+500)=709.8 \mathrm{~cm} \text {. }
$$

Therefore, it is possible to ensure a complete automation of the SDI system via the installation of an overhead basin whose water level is constant.

\section{Conclusion}

Apart from labor's reduction, the water, and energy savings, the SDI system offers the opportunity of a completely automated irrigation management. In fact, the wise control of the soil water content variation at the vicinity of the outlets is a milestone in managing subdrip irrigation. The rationale is that the flow rate of buried drippers is function of the pressure head at the soil depth of burial. Consequently, the temporal variation of the flow rates is dependent on soil water redistribution and roots water uptake. The design procedure developed in this paper provides the appropriate emitters discharge and the inlet lateral pressure head that fit the plant roots water uptake. Knowing the soil retention curve and the roots water uptake, the procedure provides guidelines to design SDI laterals. The main objective of the design is to ascertain optimal suction head within the emitters depth of burial so that irrigation events are automatically controlled by the soil moisture variations. The illustrative study case showed that soil water content could be circumscribed within an interval suitable for plant growth. This approach could be a helpful tool for the best SDI systems design and the best water supplies management. Nevertheless, it is worth to underline that the current approach completely overlooks the effect of burial on drippers' clogging.

\section{References}

[1] P. Neelam and T. B. S. Rajput, "Dynamics and modeling of soil water under subsurface drip irrigated onion," Agricultural Water Management, vol. 95, no. 12, pp. 1335-1349, 2008.

[2] L. R. Sinobas, M. Gil, L. Juana, and R. Sánchez, "Water distribution in laterals and units of subsurface drip irrigation. I: simulation," Journal of Irrigation and Drainage Engineering, vol. 135, no. 6, pp. 721-728, 2009.

[3] G. L. Grabow, R. L. Huffman, R. O. Evans, D. L. Jordan, and R. C. Nuti, "Water distribution from a subsurface drip irrigation system and dripline spacing effect on cotton yield and water use efficiency in a coastal plain soil," Transactions of the ASABE, vol. 49, no. 6, pp. 1823-1835, 2006.

[4] M. M. Kandelous and J. Šimůnek, "Numerical simulations of water movement in a subsurface drip irrigation system under field and laboratory conditions using HYDRUS-2D," Agricultural Water Management, vol. 97, no. 7, pp. 1070-1076, 2010.

[5] N. Patel and T. B. S. Rajput, "Effect of subsurface drip irrigation on onion yield," Irrigation Science, vol. 27, no. 2, pp. 97-108, 2009.

[6] E. D. Vories, P. L. Tacker, S. W. Lancaster, and R. E. Glover, "Subsurface drip irrigation of corn in the United States MidSouth," Agricultural Water Management, vol. 96, no. 6, pp. 912916, 2009.

[7] S. R. Evett, T. A. Howell, and A. D. Schneider, "Energy and water balances for surface and subsurface drip irrigated corn," in Proceedings of the 5th International Micro irrigation Congress, pp. 135-140, Orlando, Fla, USA, April 1995.

[8] J. E. Ayars, C. J. Phene, R. B. Hutmacher et al., "Subsurface drip irrigation of row crops: a review of 15 years of research at the Water Management Research Laboratory," Agricultural Water Management, vol. 42, no. 1, pp. 1-27, 1999.

[9] N. Lazarovitch, J. Šimůnek, and U. Shani, "System-dependent boundary condition for water flow from subsurface source," Soil Science Society of America Journal, vol. 69, no. 1, pp. 46-50, 2005.

[10] B. Safi, M. R. Neyshabouri, A. H. Nazemi, S. Massiha, and S. M. Mirlatifi, "Water application uniformity of a subsurface 
drip irrigation system at various operating pressures and tape lengths," Turkish Journal of Agriculture and Forestry, vol. 31, no. 5, pp. 275-285, 2007.

[11] L. R. Sinobas, M. Gil, L. Juana, and R. Sánchez, "Water distribution in laterals and units of subsurface drip irrigation. II: field evaluation," Journal of Irrigation and Drainage Engineering, vol. 135, no. 6, pp. 729-738, 2009.

[12] U. Shani, S. Xue, R. Gordin-Katz, and A. W. Warrick, "Soillimiting flow from subsurface emitters. I: pressure measurements," Journal of Irrigation and Drainage Engineering, vol. 122, no. 5, pp. 291-295, 1996.

[13] W. W. Yao, X. Y. Ma, J. Li, and M. Parkes, "Simulation of point source wetting pattern of subsurface drip irrigation," Irrigation Science, vol. 29, no. 4, pp. 331-339, 2011.

[14] M. Gil, L. R. Sinobas, L. Juana, R. Sánchez, and A. Losada, "Emitter discharge variability of subsurface drip irrigation in uniform soils: effect on water-application uniformity," Irrigation Science, vol. 26, no. 6, pp. 451-458, 2008.

[15] P. D. Colaizzi, A. D. Schneider, S. R. Evett, and T. A. Howell, "Comparison of SDI, LEPA, and spray irrigation performance for grain sorghum," Transactions of the American Society of Agricultural Engineers, vol. 47, no. 5, pp. 1477-1492, 2004.

[16] N. Lazarovitch, The effect of soil water potential, hydraulic properties and source characteristic on the discharge of a subsurface source [Ph.D. thesis], Faculty of Agriculture of the Hebrew University of Jerusalem, 2008.

[17] B. E. Clothier and S. R. Green, "Roots: the big movers of water and chemical in soil," Soil Science, vol. 162, no. 8, pp. 534-543, 1997.

[18] Z. Khemaies and H. Moncef, "Design of level ground laterals in trickle irrigation systems," Journal of Irrigation and Drainage Engineering, vol. 135, no. 5, pp. 620-625, 2009.

[19] M. T. Van Genuchten, "A closed-form equation for predicting the hydraulic conductivity of unsaturated soils," Soil Science Society of America Journal, vol. 44, no. 5, pp. 892-898, 1980.

[20] Y. Mualem, "A new model for predicting the hydraulic conductivity of unsaturated porous media," Water Resources Research, vol. 12, no. 3, pp. 513-522, 1976.

[21] A. Ben-Gal, N. Lazorovitch, and U. Shani, "Subsurface drip irrigation in gravel-filled cavities," Vadose Zone Journal, vol. 3, no. 4, pp. 1407-1413, 2004.

[22] J. Doorenbos, A. H. Kassem, C. L. M. Bentverlsen et al., "Yield Response to water," FAO Paper 33, 1987.

[23] K. Y. Li, R. De Jong, and J. B. Boisvert, "An exponential rootwater-uptake model with water stress compensation," Journal of Hydrology, vol. 252, no. 1-4, pp. 189-204, 2001.

[24] A. I. Gärdenäs, J. W. Hopmans, B. R. Hanson, and J. Šimůnek, "Two-dimensional modeling of nitrate leaching for various fertigation scenarios under micro-irrigation," Agricultural Water Management, vol. 74, no. 3, pp. 219-242, 2005.

[25] B. R. Hanson, J. Šimůnek, and J. W. Hopmans, "Evaluation of urea-ammonium-nitrate fertigation with drip irrigation using numerical modeling," Agricultural Water Management, vol. 86, no. 1-2, pp. 102-113, 2006.

[26] R. S. Clemente, R. De Jong, H. N. Hayhoe, W. D. Reynolds, and M. Hares, "Testing and comparison of three unsaturated soil water flow models," Agricultural Water Management, vol. 25, no. 2, pp. 135-152, 1994.

[27] M. Hammami and K. Zayani, "Effect of trickle irrigation strategies on tomato yield and roots' distribution," World Journal of Agricultural Sciences, vol. 5, pp. 847-855, 2009.
[28] W. Qingsong, S. Yusheng, D. Wenchu, L. Gang, and H. Shuhuai, "Study on hydraulic performance of drip emitters by computational fluid dynamics," Agricultural Water Management, vol. 84, no. 1-2, pp. 130-136, 2006.

[29] G. Z. Watters and J. Keller, “Trickle irrigation tubing hydraulics," Tech. Rep. 78-2015, ASCE, Reston, Va, USA, 1978.

[30] L. Juana, L. R. Sinobas, A. Losada, and M. Asce, "Determining minor head losses in drip irrigation laterals. I: methodology," Journal of Irrigation and Drainage Engineering, vol. 128, no. 6, pp. 376-384, 2002. 


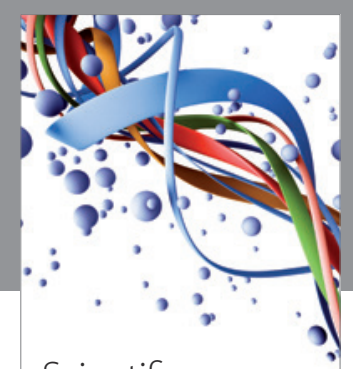

Scientifica
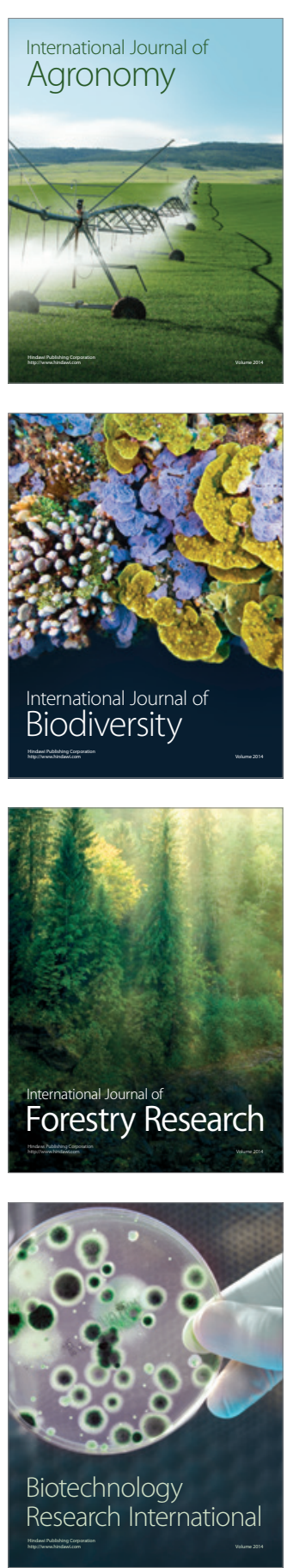
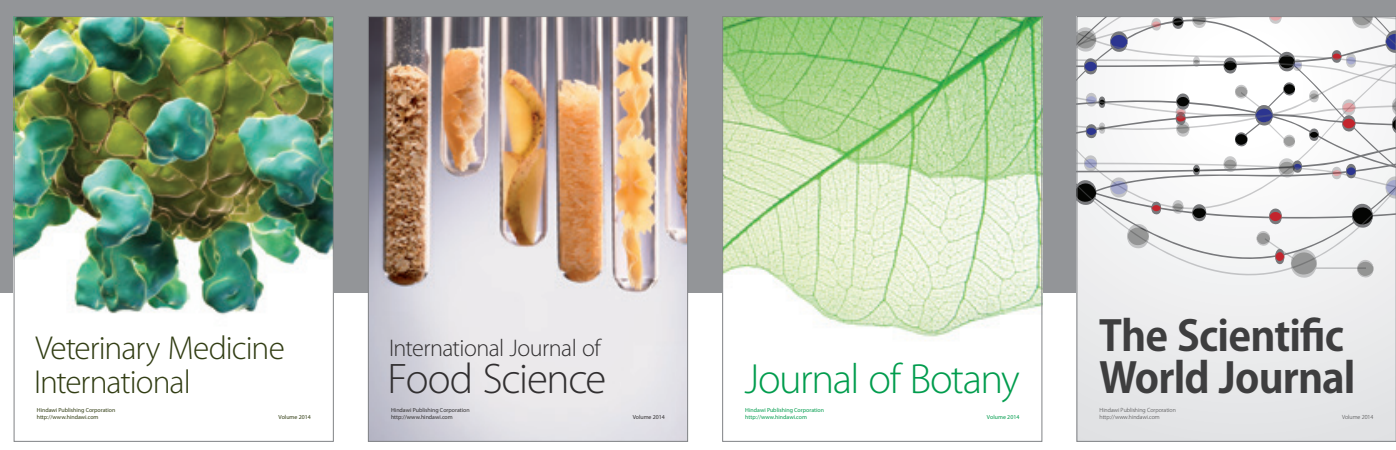

The Scientific World Journal
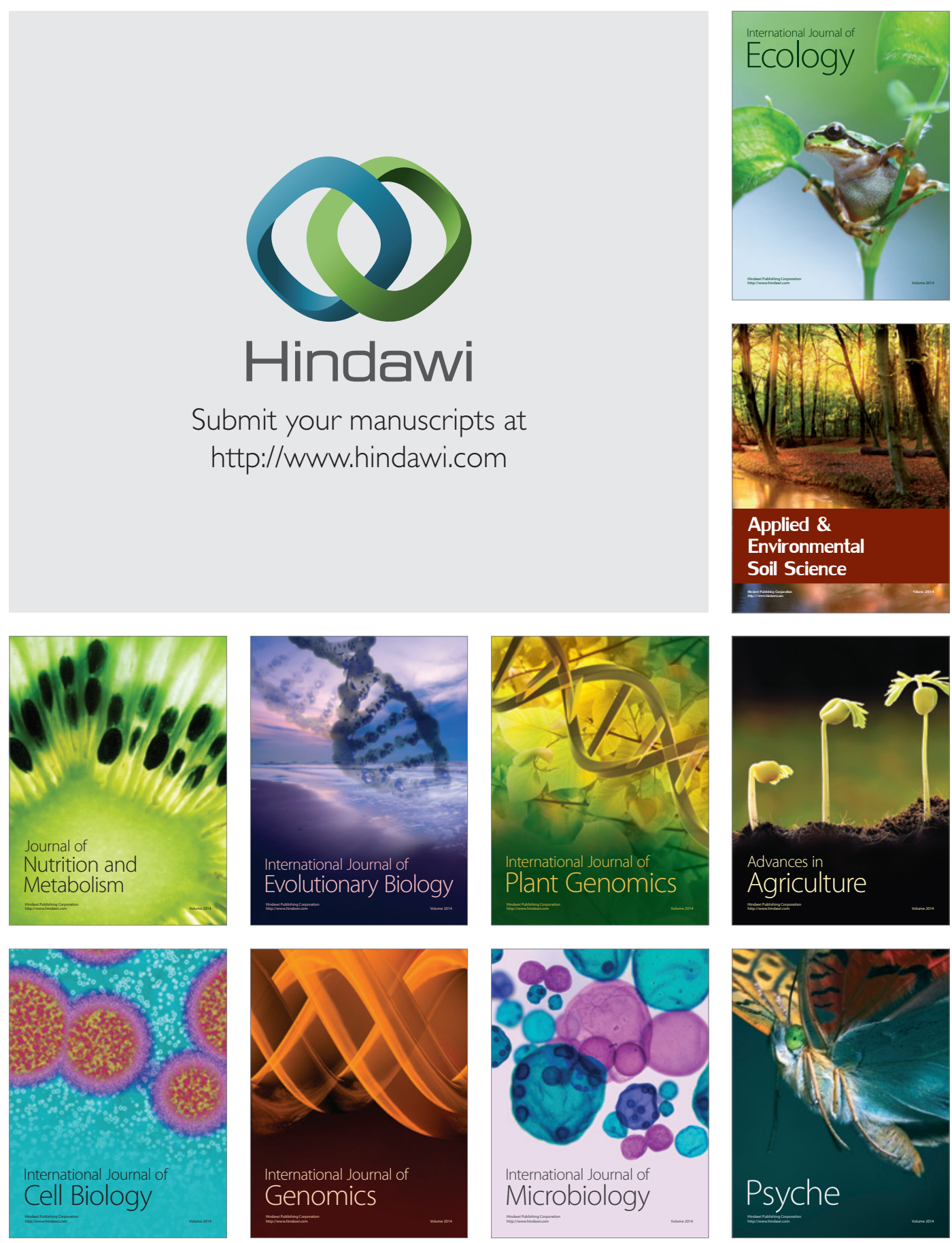